\title{
A ADMIRAÇÃO À LUZ DOS CORPOS
}

\author{
DIANA SANTOS E CRISTINA MOTA
}

\section{RES UMO}

This paper studies the field of admiração in their two meanings in Portuguese, namely: veneration/respect and surprise, using the framework suggested in Belinda Maia's PhD thesis (Maia 1994/1996). After presenting briefly her findings and methodology, we investigate (i) the distribution of the vague words of the field of admiração by the two meanings, and discuss the heuristics used in its rule-based distinction; (ii) the distribution of admiração by genre, tense and person; (iii) its presence in negative sentences; and (iv) its antonym(s).

A forma como as emoções são mencionadas e descritas numa língua é uma janela para o tecido social de um povo e de uma cultura. Belinda Maia foi pioneira ao usar um método contrastivo para iluminar as diferenças entre as suas duas culturas. Passados vinte anos, o trabalho dela continua atual e as suas descobertas muitos interessantes, embora tenham tido bastante menos impacto do que mereciam. Este artigo é, pois, um tributo ao seu trabalho pioneiro e um contributo, embora modesto, para o estudo das emoções em português. Após (re)apresentarmos as conclusões obtidas em Maia e tentarmos compará-las, do lado português, com dados obtidos nos nossos corpos, apresentamos vários estudos originais sobre as palavras associadas a admiração, que, em português, tem dois sentidos distintos, embora relacionados: surpresa e veneração/respeito.

De um ponto de vista eminentemente prático, se conseguirmos uma boa separação / distinção entre admiração-respeito, sentimento positivo tanto em relação ao sujeito como ao objeto, e admiração-espanto, neutro e até possivelmente negativo em relação ao objeto, podemos contribuir para uma melhoria dos sistemas de apreciação na nossa língua, quer publicando as regras, quer tornando os corpos da Gramateca (Santos 2014b), devidamente anotados, acessíveis a todos para treinar os seus sistemas. Isso significa que podemos também satisfazer a Belinda em mais esse traço do seu caráter - pragmatismo generoso, ou generosidade pragmática - em vez das torres de marfim académicas que ela às vezes lamenta.

\section{[1] APRESENTAÇÃ O}

Este artigo estuda a admiração (nas suas duas vertentes, espanto/surpresa e veneração/respeito) em português, usando o enquadramento teórico proposto por Belinda Maia (Maia 1994/1996) na sua tese de doutoramento, e pretende ser assim 
também uma prova da admiração que temos por ela e pelo seu trabalho, como colaboradoras e amigas há muitos anos.

Em particular, discutimos as seguintes questões:

- distribuição por género de texto;

- distribuição por pessoa e por tempo;

- qual a sua presença em frases negativas;

- como distinguir os dois sentidos acima referidos;

- a existência de um oposto da admiração.

O trabalho tem como enquadramento mais vasto a anotação de emoções no âmbito da Gramateca, que pressupõe, como exposto em Santos \& Mota (2010), a revisão da anotação automática com a necessária adição da interpretação humana nos casos mais complicados, de forma a obter uma anotação $100 \%$ coerente. Em Santos \& Mota (2015) apresentamos uma visão global do campo das emoções, enquanto neste artigo nos concentramos na surpresa e na veneração, ambas passíveis de descrição em português pela palavra admiração.

Dado que a fundamentação teórica e a inspiração vêm da tese de doutoramento de Belinda Maia, começamos por apresentar brevemente, na secção seguinte, os instrumentos de trabalho aí propostos, bem como os campos lexicais associados ao conceito de admiração.

\section{[2] A EMOÇÃO EM INGLÊS E EM PORTUGUÊS}

Belinda Maia, na sua tese de 1994 (note-se que usamos como versão legítima, como é o desejo da autora, a versão revista de 1996), dedicou-se ao estudo linguístico da emoção nas "suas" duas línguas, usando para isso um corpo comparável (coligido, digitalizado e analisado por ela) de textos literários, de 778.500 palavras em inglês e 819.500 em português, produzindo cerca de 25 mil exemplos de emoção (somando as duas línguas). Após rever a literatura extensa sobre as emoções na língua, decide-se pela abordagem linguística, ou seja, não partindo de postulados psicológicos ou filosóficos, mas sim da forma como as duas línguas funcionam, para a sua categorização. É inspirada sobretudo por Ortony et al. (1988), que usa como ponto de partida:

I propose to adopt Ortony et al's (1988) classification of emotion groups, and add to it when necessary. (Maia 1994/1996, secção 4.5)

Uma das razões aduzidas é que a teoria deles não está "colada" ao inglês, visto que faz uma diferença entre a situação da emoção e a palavra da emoção, e daí oferece mais possibilidades para uma análise bilingue. 
Muito resumidamente, Belinda Maia usa os seguintes instrumentos de trabalho ao cartografar as emoções em português e em inglês:

(i) assume que numa emoção existe sempre o "sentidor" (senser) e o fenómeno (que inspira a emoção);

(ii) em relação ao sentidor, considera interessante distinguir entre a expressão de emoções próprias ou doutros;

(iii) em relação ao fenómeno ou estímulo, ela propõe onze tipos de estímulos diferentes, sendo o primeiro não especificado, os quatro seguintes associados ao sentidor, os próximos quatro associados ao "outro" no sentido do diálogo, e finalmente os últimos dois referindo-se quer a um objeto (não humano, portanto) quer a uma proposição.

Belinda Maia estudou 17 emoções, concetualmente divididas em quatro grupos, nomeadamente anger (3), appreciation (3), disappointment (2), dislike (4), distress (1), fear (2), gratitude (3), hope (2), joy (1), liking (4), pride (3), relief (2), reproach (3), resentment (1), satisfaction (2), self-reproach (3), sorry for (1). A descrição do grupo, acima marcado simplesmente pelo número, é dada a seguir: 1) reação a acontecimentos (em que é interessante que não existem, segundo ela, alegria pela felicidade ou infelicidade dos outros ${ }^{1}$ nas duas línguas estudadas); 2) reações a acontecimentos projetados (em que mais uma vez o grupo logicamente possível de "medos confirmados" não tem expressão lexical em nenhuma das línguas); 3) reações a agentes; 4) reações a objetos, sobre as quais Belinda Maia comenta que amor e ódio, arquetípicas emoções para um leigo, não são consideradas emoções básicas por vários teóricos ${ }^{2}$. Note-se que é interessante que não são considerados como emoção os campos - na nossa opinião possíveis - de ingratidão e de coragem, enquanto a saudade é um subtipo de distress e a vergonha está incluída no grupo de self-reproach/remorse.

Além disso, ela também refere e estuda - indicando que estão fora do esquema de Ortony et al. (1988) - as seguintes possíveis emoções: surpresa, desejo, e "emoção genérica" (compreendendo palavras como sentir, emocionar, emoção, sentimento).

Para dar uma pequena ideia do tipo de dados fornecidos na tese de Belinda Maia, apresentamos aqui a sua análise referente a surpresa, com as tabelas publicadas em relação à distribuição dos lexemas. Em inglês: surprise (48,5\%), amaze

[1] O que não significa que não seja possível sentir essas emoções sem palavras a elas dedicadas. De facto, Belinda Maia demonstra a sua alegria precisamente pelo facto de a língua portuguesa não ter um equivalente lexical da palavra gloat, que aliás era muito rara no seu corpo inglês também. Mas happy for é apenas uma variante de happy, o que não exige portanto um campo à parte.

[2] Embora em língua inglesa exista uma atenção gramatical sobre a distinção entre animado e não animado, tal não acontece em português, donde poderia fazer algum sentido juntar os 3 e 4 num mesmo grupo dizemos nós, que somos falantes de português. 
$(19,3 \%)$, startle (12,4\%), astonish (12,1\%), e outras seis palavras cobrindo os restantes $7,7 \%$. Em português, surpreender $(35,4 \%)$, espantar $(23,9 \%)$, pasmar $(13,4 \%)$, assombrar (11,3\%) e admirar (9,5\%). É interessante, do nosso ponto de vista, reparar que a maior parte destas palavras em português são ambíguas, ou pelo menos podem significar outras coisas também: além de admirar, que é o tema do nosso artigo, atente-se nas seguintes frases: Ele surpreendeu-os na fronteira; Esse cheiro espanta as moscas; A casa estava assombrada.

A tabela 13.1, repetida aqui na forma de quatro tabelas diferentes (tabelas 14), indica a proporção dos casos em que a emoção (de surpresa) é orientada para o sentidor (S), ou para o fenómeno (P), assim como quantos casos são descrições de comportamento ${ }^{3}$.

\begin{tabular}{rrr}
\hline SURPRISE & & \\
\hline GENERAL & English & Portuguese \\
S focus \% & 66,7 & 62,5 \\
P focus \% & 33,3 & 37,5 \\
beh \% & 22,3 & 22,1 \\
\hline
\end{tabular}

TABELA 1: O campo da surpresa no material de Maia, primeira panorâmica

A questão do comportamento (marcada por "beh") é outra das distinções que Belinda Maia faz na sua anotação, devido à questão filosófica da diferença entre comportamento associado a uma emoção e emoção propriamente dita. Citamos o seu texto sobre o assunto, cf. Maia (1994/1996, secção 4.4):

When an emotional situation is being described seriously, there appear to be three main ways in which emotion words, at least in English and Portuguese, function in these descriptions: 1 a) to describe the Subject, or Senser's, emotional state or processes, as in I love you, $\mathrm{He}$ is angry with you, or I feel depressed; $1 \mathrm{~b}$ ) to describe the behaviour associated with the emotional processes or state, as in He looked terrified, She sounded upset or They waited anxiously; 2 . to describe the qualities or behaviour of the Object of the emotion, or Phenomenon, as in He annoys me, She is irritating or The kitten is adorable. The difference between $1 a$ ) and $b$ ) is that the former assumes the existence of the emotion, whereas the latter is more tentative and merely describes the behaviour that might indicate it.

Além de chamar a atenção para esta distinção, Belinda Maia tem o cuidado de marcar cada caso que considera descrição de comportamento. Isso é, aliás, especialmente relevante no campo da surpresa, visto que, segundo ela, os casos de

[3] Outra questão mencionada, e anotada por Belinda Maia, foi a de "deliberate" (deliberadamente) quando um dado fenómeno tem como intenção provocar a emoção. 


\begin{tabular}{rrrrrrrrr}
\hline & \multicolumn{4}{c}{ English } & \multicolumn{5}{c}{ Portuguese } \\
& S focus & P focus & totals & $\%$ & S focus & P focus & totals & $\%$ \\
\hline 1 & 3 & & 3 & 0,8 & 19 & 7 & 26 & 5,6 \\
2 & & & & & 1 & 3 & 4 & 0,9 \\
3 & 5 & & 5 & 1,4 & 4 & & 4 & 0,9 \\
4 & 37 & 7 & 44 & 12,1 & 12 & 7 & 19 & 4,1 \\
5 & 7 & 3 & 10 & 2,8 & 5 & 4 & 9 & 2 \\
6 & 5 & 3 & 8 & 2,2 & 9 & 27 & 36 & 7,8 \\
7 & 11 & 6 & 17 & 4,7 & 7 & 8 & 15 & 3,3 \\
8 & 8 & 7 & 15 & 4,1 & 6 & 3 & 9 & 2 \\
9 & 135 & 43 & 178 & 49 & 165 & 53 & 218 & 47,3 \\
10 & 25 & 42 & 67 & 18,5 & 49 & 56 & 105 & 22,8 \\
11 & 6 & 10 & 16 & 4,4 & 11 & 5 & 16 & 3,5 \\
\hline Total & 242 & 121 & 363 & & 288 & 173 & 461 & \\
\hline
\end{tabular}

TABELA 2: Qual o fenómeno inspirador de surpresa?

pasmar seriam mais naturalmente descritos em inglês como he gaped in amazement ou his jaw dropped in surprise. Nós podemos adicionar, para o português, Ficou de boca aberta, ou mesmo Os olhos iam-lhe saltando das órbitas. No seu corpo, encontrou mais de $20 \%$ dos casos descrevendo comportamento.

A tabela 2 detalha, nas duas línguas, o tipo de fenómeno associado à surpresa.

As tabelas 3 e 4 indicam, respetivamente para os casos focados no sentidor (Sfoc) e os no fenómeno (Pfoc), a forma sintática em que aparecem.

\begin{tabular}{rrrrr}
\hline Sentidor & Total EN & \% & Total PT & \% \\
\hline S-adj-att & & & 8 & 1,7 \\
S-adj-pr & 4 & 1,1 & 6 & 1,3 \\
S-pp-att & 16 & 4,4 & 15 & 3,3 \\
S-pp-pr & 133 & 36,6 & 107 & 23,2 \\
S-adv & 1 & 0,3 & & \\
S-n & 88 & 24,2 & 110 & 23,9 \\
S-v & & & 42 & 9,1 \\
S-v-se & & & & \\
\hline
\end{tabular}

TABELA 3: No caso de surpresa focada no sentidor, qual a forma sintática?

Em relação a estes dados, Belinda considera haver uma grande percentagem de adjetivos (referentes ao sentidor), sobretudo em inglês (41\%), mas também em português $(26,5 \%)$, e de particípios passados: aqui repare-se na diferença de com- 


\begin{tabular}{rrrrr}
\hline Fenómeno & Total EN & \% & Total PT & \% \\
\hline P-adj-att & 28 & 7,7 & 8 & 1,7 \\
P-adj-pr & 26 & 7,1 & 5 & 1,1 \\
P-pp-att & & & & \\
P-pp-pr & & & & \\
P-adv & 21 & 5,9 & 3 & 0,7 \\
P-n & 16 & 4,4 & 69 & 15 \\
P-v & 30 & 8,3 & 59 & 12,8 \\
P-v-se & & & 29 & 6,3 \\
\hline
\end{tabular}

TABELA 4: No caso de surpresa focada no fenómeno, qual a forma sintática?

plementação entre o inglês, com $53,3 \%$, e o português, com apenas $29 \%{ }^{4}$. Outra questão sublinhada por ela é que em português existe um grande número de casos orientados ao sentidor com a cópula ficar $(25,2 \%)$ e com quase-cópulas como parecer (sobre as quais não apresenta valores), enquanto adjetivos e advérbios relacionados com o fenómeno são raros - ao contrário do inglês, em que são muito frequentes.

Belinda Maia também menciona a ambivalência de todos os substantivos relativos ao fenómeno (nas duas línguas), em que "ambivalência" significa que podem ser (fora do contexto) tanto associados ao fenómeno como ao sentidor: por exemplo (o exemplo é nosso), surpresa é ambivalente porque aceita A surpresa da Maria (Sfoc) ou A surpresa por ele não ter vindo (Pfoc).

Duas diferenças interessantes entre as línguas são: o inglês (pelo menos nos corpos usados por Belinda Maia) não tem verbos associados ao sentidor, enquanto o português tem (admirar-se de ... ou pasmar-se com), produzindo 9,1\% de casos; além disso, os verbos associados ao fenómeno são mais frequentes em português $(19,1 \%)$ do que em inglês $(8,3 \%)$. Ela também relata outros casos típicos das línguas em questão: o it existencial para o inglês, como em It did not surprise me to find..., e a construção portuguesa há coisas de espantar.

Outro tema focado por Belinda Maia é a complexidade da análise dos verbos de surpresa reflexivos: ela menciona 29 exemplos de um tipo semi-reflexivo, a maior parte referente a admirar-se, comentando que nalguns casos a classificação entre Sfoc e Pfoc foi arbitrária.

E terminamos aqui este exemplo da riqueza de informações e de análises presente em Maia (1994/1996): uma secção de três páginas numa tese de quatrocentas demonstra o quanto foi feito, e é verdadeiramente admirável. Não admira, tam-

[4] Tal pode apreciar-se mais facilmente se esquecermos a diferença entre adjetivo e particípio passado, com a mesma vagueza nas duas línguas (Santos 1998), e somarmos as linhas S-adj e S-pp: 153 casos em inglês (En) e 136 em português (Pt). 
bém, que muito se possa aproveitar para repetir e esmiuçar melhor - o que é o objetivo confesso do presente artigo, no lado do português. Mas pensamos que se torna óbvio para qualquer leitor que existirão muitos outros tesouros na sua tese, e, sublinhamos, razões para a ler, tanto pela clareza da discussão como por opiniões muito interessantes sobre a própria gramática portuguesa.

\section{[3] A ADMIRAÇÃO NOS CORPOS DO AC/DC}

A primeira coisa que gostaríamos de fazer seria uma comparação com os dados relativos ao português compilados na tese de Belinda Maia, para ver se mais dados permitem mais conhecimento, ou se a amostra dela era suficientemente representativa já.

Em princípio, podemos estudar quer textos literários apenas, quer toda a língua a que temos acesso, veja-se Santos (2014a) para uma descrição breve do enquadramento.

Alguns problemas, contudo, se nos deparam. Em primeiro lugar, consideramos que os dados acima referidos se referem apenas a surpresa (visto que foram todos submetidos a rigoroso escrutínio por Belinda Maia) mas, de momento, alguma parte do que está marcado como surpresa pode referir-se realmente a veneração ou respeito, visto que a distinção entre os dois ainda não foi cabalmente operacionalizada e revista, veja-se a secção [4].

A noção de veneração poderá, portanto, no caso de ter um perfil sintático muito diferente e ser suficientemente frequente, confundir os números relativos à distribuição sintática da surpresa, que apresentamos na tabela 5. À medida que essa desambiguação for incluída no AC/DC, poderemos obter valores mais confiáveis.

A outra dificuldade, que é mais difícil de contornar, é a de que centenas de milhões de palavras não permitem a análise tão detalhada em termos, por exemplo, da orientação para o sentidor e para o fenómeno, e por isso a comparação terá de ser feita por categorias menos finas, em particular, amalgamando as tabelas 3 e 4 apenas por categoria gramatical, na coluna "Maia".

\begin{tabular}{lrrrrrr}
\hline & Maia & \% & Literário & \% & Todos & \% \\
\hline $\mathrm{V}$ & 130 & 28,2 & 4490 & 30,0 & 60925 & 28,6 \\
$\mathrm{~N}$ & 179 & 38,8 & 3845 & 25,6 & 55047 & 25,9 \\
$\mathrm{ADJ}$ & 27 & 5,8 & 4462 & 29,8 & 79349 & 37,3 \\
$\mathrm{PP}$ & 122 & 26,5 & 1033 & 6,9 & 6725 & 3,2 \\
$\mathrm{ADV}$ & 3 & 0,65 & 1160 & 7,7 & 10723 & 5,0 \\
total & 461 & & 14990 & & 212769 & \\
\hline
\end{tabular}

TABELA 5: A distribuição por categoria gramatical da surpresa nos vários corpos 
A maior diferença é claramente na percentagem dos adjetivos, mas a distinção entre adjetivos, particípios passados e formas passivas do verbo é uma das tarefas mais espinhosas e menos consensuais na gramática da nossa língua... $\mathrm{O}$ facto de que a soma ADJ + PP não difere muito nos três materiais parece-nos resolver esta eventual disparidade de forma relativamente satisfatória.

Por outro lado, para casos com frequência muito baixa no material original, como são os apenas três advérbios, é natural que haja diferenças significativas quando se observam amostras muito maiores.

O que ressalta como interessante e inesperado, desta comparação a três níveis é a semelhança dos valores literários com o resto da língua, constituindo ainda por cima o corpo literário declarado apenas 7\% do total. Por isso na secção [3.1] vamos olhar com mais cuidado para a questão do género.

A partir de agora, daremos uma panorâmica do campo admiração + surpresa (em que admiração significa neste caso veneração), deixando para a secção [4] a explicação de como atacámos essa distinção mais fina.

\section{[3.1] Distribuição por género textual}

$\mathrm{Na}$ figura 1 apresentamos a distribuição do material por género do texto. Contudo, é preciso reconhecer que o conceito de género também não é nada simples de fixar. Veja-se Santos (2015) para uma discussão dos conceitos e das escolhas envolvidas, e Freitas \& Santos (2015) para a questão do género blogue.

Vemos que o género onde a admiração é mais frequente é o das recensões do corpo ReLi (Freitas et al. 2014) seguido pelos blogues da Amazônia, e pelo texto literário. A surpresa - sempre mais frequente do que a admiração - é mais frequente na literatura (traduzida e original) e nas recensões de livros, tendo em conta que também faz parte da arte dramática. Não será surpresa verificar que no texto legal, técnico e académico nenhuma destas emoções é frequente. Por outro lado já é mais interessante constatar que o texto enciclopédico, assim como o oral informal, são os únicos que apresentam a mesma proporção de supresa e admiração. Todos os outros géneros contêm (muito) mais surpresa.

\section{[3.2] Distribuição por tempo verbal}

Uma questão interessante é saber qual a distribuição de uma emoção de acordo com os tempos verbais, e se é diferente da distribuição das outras emoções ou do próprio texto em geral.

Como este assunto não se esgota facilmente, escolhemos aqui testar se a nossa intuição referente aos dois tipos de emoções pode ser confirmada pelos dados gerais, ainda sem distribuição por sentido, mas com a seguinte hipótese:

- a admiração no sentido de respeito refere-se sobretudo a tempos estativos, generalizadores, e será portanto encontrada principalmente no presente e no imperfeito; 


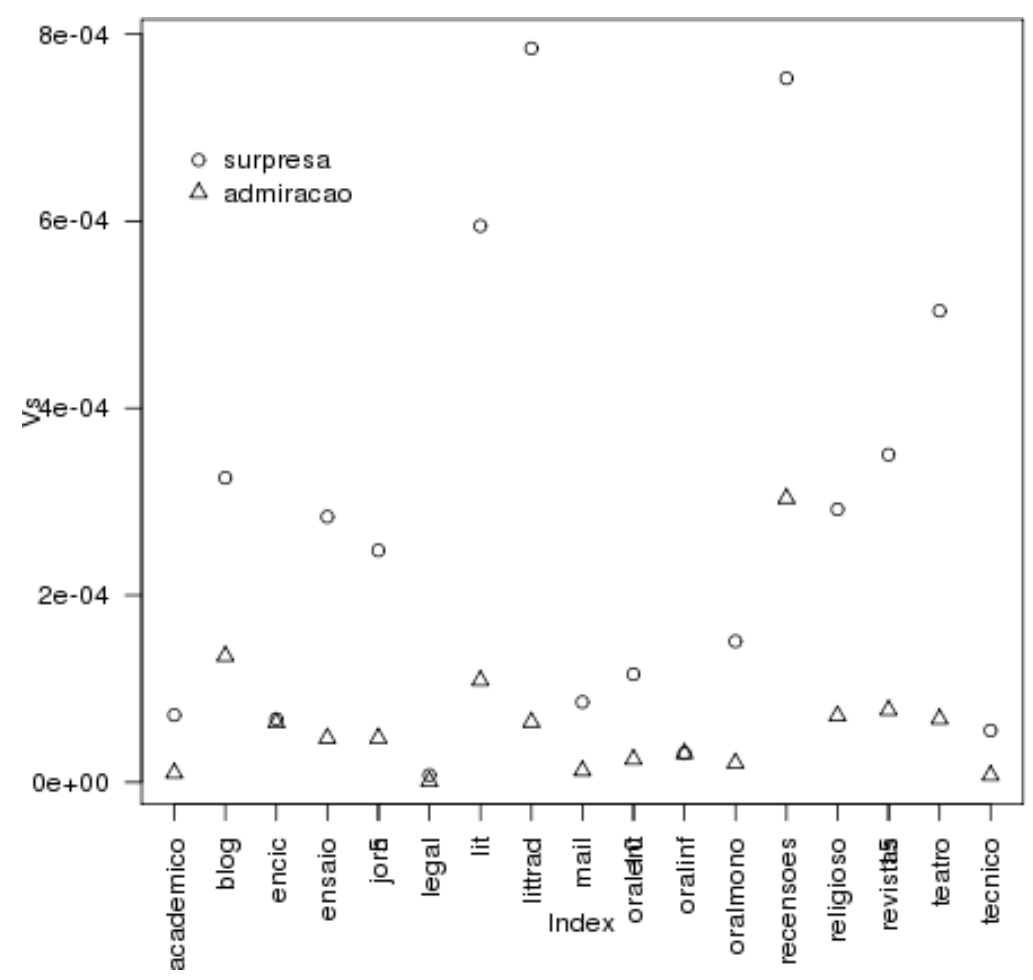

FIGURA 1: Admiração e surpresa nos corpos da Gramateca.

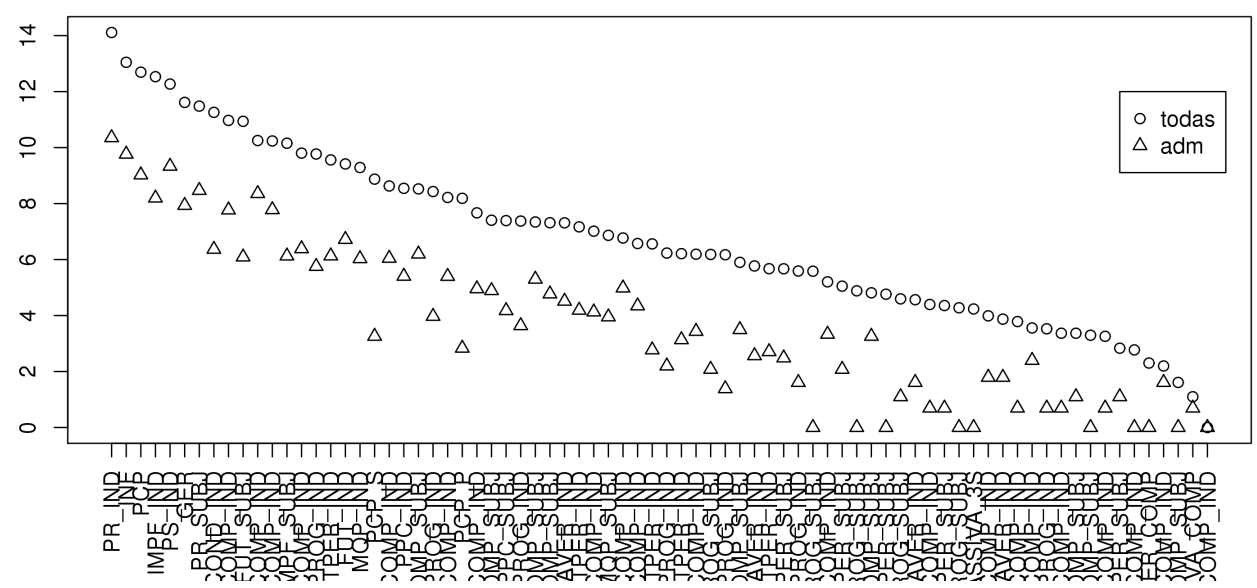

FIGURA 2: Distribuição da admiração comparada com todas as emoções nos corpos da Gramateca, por tempo verbal (explicação das abreviaturas no sítio do AC/DC). 
- a surpresa é algo que se experimenta, é temporário e fixo no tempo, por isso será (muito) mais usado na passiva e com o perfeito.

Note-se que temos a possibilidade de olhar para o tempo verbal dos verbos de emoção, ou para o tempo verbal das frases em que uma palavra de emoção ocorre, e que esses dois tipos de números serão ou poderão ser completamente diferentes. Neste caso escolhemos o mais fácil de investigar, que se refere às formas verbais, mas que pode proporcionar algum viés, visto que não abarca o campo semântico global.

Na figura 2, comparamos as emoções verbais todas com a admiração (em logaritmo). O mais interessante, naturalmente, são os casos em que a distribuição não seja semelhante. Da inspeção da figura, os casos mais gritantes são, aparentemente, mais casos de perfeito e menos casos de imperfeito do que a média das emoções, e significativamente mais casos de passiva no infinitivo.

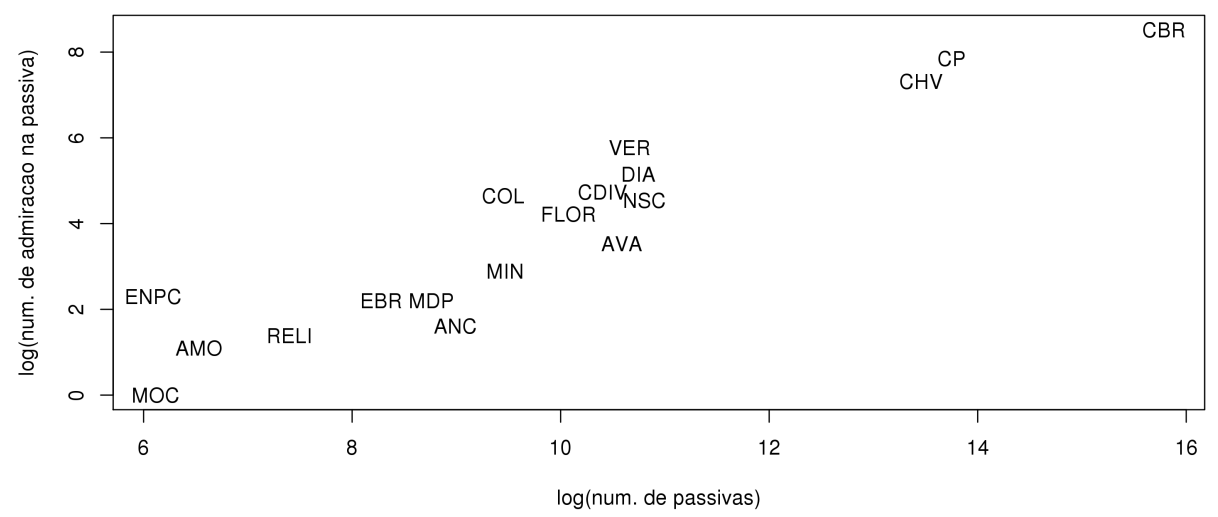

FIGURA 3: Relação entre passiva em geral e admiração na passiva, por corpo.

Na figura 3, olhamos para a ocorrência do campo da admiração na passiva, por corpo. De forma a compará-los, apresentamos o logaritmo do número de passivas no eixo dos XX e o logaritmo das referentes à admiração no eixo dos YY. Os corpos ENPC (texto literário traduzido do inglês), COLONIA (que por ter um texto sobre emoções tem sempre mais de tudo) e o Vercial (texto literário desde 1500) têm mais admiração na passiva do que o resto do material, enquanto que a lista do ANCIB e o jornal Avante têm menos. 


\section{[3.3] Distribuição por pessoa}

$\mathrm{E}$ o mesmo fizemos em relação à pessoa ${ }^{5}$. Não querendo nem podendo esgotar aqui todas as possibilidades de investigação, resolvemos concentrar-nos em dois corpos distintos: o Museu da Pessoa ${ }^{6}$, que, como já foi dito, é centrado sobre a história pessoal dos entrevistados, e tem, portanto, mais percentagem de primeira pessoa que outros textos; e o CONDIV, contendo jornalismo especializado sobre três temas distintos - futebol, moda e saúde, e que se esperaria que tivesse uma percentagem muito maior de terceira pessoa, como se pode observar na tabela $6^{7}$.

\begin{tabular}{lrrrr}
\hline & MP 1a & MP 3a & CONDIV 1a & CONDIV 3a \\
\hline $\mathrm{S}$ & 44867 & 121171 & 18880 & 336832 \\
$\mathrm{P}$ & 10740 & 23713 & 19514 & 104791 \\
Total & 71186 & 185539 & 69480 & 610251 \\
admir S & 21 & 3 & 27 & 367 \\
admir P & 17 & 6 & 27 & 63 \\
admir total & 26 & 31 & 60 & 642 \\
\hline
\end{tabular}

TABELA 6: A distribuição da pessoa

Nessa tabela vemos que os verbos marcados com os valores de surpresa ou respeito são mais frequentes, relativamente, na primeira pessoa no Museu da Pessoa (3,65e-4 na primeira contra 1,67e- 4 na terceira), mas no CONDIV são mais frequentes na terceira 1,05e-3 do que na primeira, $8,64 \mathrm{e}-4)$.

Mais marcada é a diferença entre o singular e o plural, cuja explicação cabal terá de ficar para o futuro: mesmo na terceira pessoa, o singular tem sempre muito mais casos. Tal não deverá contudo ser surpreendente, na medida em que será mais natural falarmos das emoções ou estados de espírito de um indivíduo do que duma pluralidade.

Mas, para indagarmos se o que observámos em relação aos valores de admiração é uma propriedade especial da admiração ou das emoções em geral, temos de comparar com o perfil de todas as emoções, em ambos os corpos ou em todos.

[5] Para facilitar a reprodução dos nossos resultados, apresentamos a forma de extrair os dados utilizada: [pos="V.*"\& pessnum="1S.*"\& sema=" *emomin: (surpresaladmirar) $*$ *]

[6] Os dados das tabelas que se seguem referem-se à versão do Museu da Pessoa de Setembro de 2014. Ao revermos o artigo em Janeiro de 2015, demo-nos conta de que o panorama quantitativo (automático) tinha mudado radicalmente, por termos adicionado - talvez temporariamente - o conceito de respeito (e como tal todas as palavras a ele associadas) à noção de admiração. Mas como essa questão não é relevante para a distinção entre os dois sentidos de admiração (que focamos no presente artigo) e, para termos valores fiáveis, teríamos ainda de efetuar nova desambiguação entre respeito-veneração e respeito-medo, decidimos não incorporar os novos valores no artigo.

[7] O observador atento poderá reparar que na primeira pessoa existem mais casos no total do que a soma de $S$ com P... o que se deve aos casos marcados pelo PALAVRAS como $1 / 3 \mathrm{~S}$, e que foram arbitrariamente considerados nesta tabela como primeira pessoa. Igualmente, os casos em excesso de terceira pessoa referem-se ao uso do infinitivo impessoal, que não é marcado nem com $\mathrm{S}$ nem com $\mathrm{P}$. 
$\mathrm{Na}$ figura 4, apresentamos o peso das várias emoções na primeira e terceira pessoas do singular e do plural nos dois corpos investigados, remetendo os leitores para Santos (2015) para mais discussão sobre a dificuldade de estudar a pessoa semântica em português.
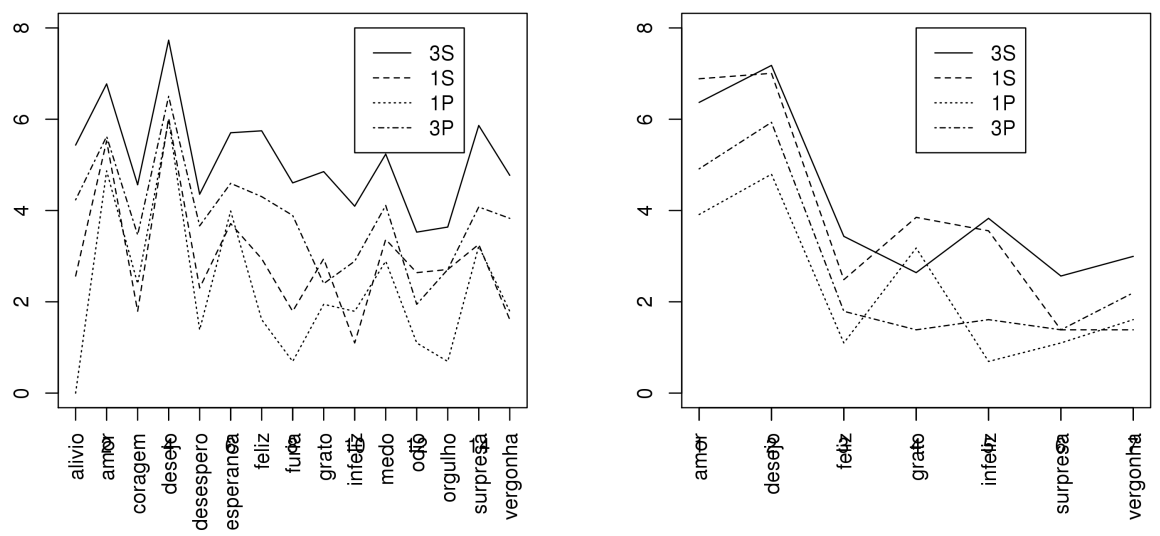

FIGURA 4: Distribuição da admiração por primeira ou terceira pessoa nos corpos ConDiv (à esquerda) e Museu da Pessoa (à direita).

\section{[3.4] Presença em frases negativas}

Outro assunto que já mencionámos como de certo interesse em relação à emoção é a sua presença ou caracterização em frases negativas, que foi estudada com algum pormenor em relação ao binómio medo-coragem em Maia \& Santos (2012). Nesse artigo, foi afirmado - correspondendo a uma versão anterior do material - que apenas obtivemos 2.951 casos de negação de medo verbal em 27.113 casos no total.

Embora nenhum dos estados de espírito a que este artigo se refere tenha um oposto lexical óbvio, como era o caso de coragem, é interessante verificar que não é muito mais frequente a sua negação do que no campo do medo, pese embora a falta de algo que exprima "falta de surpresa" ou "falta de respeito" 8 , como se pode apreciar na tabela 7.

\section{[4] A DISTINÇÃO ENTRE AS DUAS ADMIRAÇÕES}

Como já por várias vezes mencionado, uma característica interessante da língua portuguesa é associar à palavra admirar dois sentidos que noutras línguas são le-

[8] A palavra desrespeito denota falta de respeito, mas não como atitude ou emoção, e sim como ação. Não se pode dizer ele tinha desrespeito por ela, ou senti uma grande desrespeito, mas apenas Isso/essa ação foi um grande desrespeito. 


\begin{tabular}{lrrr}
\hline & medo & coragem & admiração \\
\hline negado & 1646 & 2033 & 633 \\
total & 164.046 & 194.959 & 71.674 \\
$\%$ & 1.0 & 1.04 & .88 \\
\hline
\end{tabular}

TABELA 7: A proporção das emoções (verbais), negadas ou não, no conjunto de todos os corpos

xicalmente bem separados, e que denotaremos para facilidade de compreensão no presente artigo a partir de agora sempre por surpresa e veneração.

Começamos por tentar proceder a uma distinção entre as duas "admirações" no caso da base admirar. Embora fosse extremamente interessante conhecer a história desta palavra ou família de palavras, não a consideraremos aqui.

Usado reflexivamente, admirar-se significa quase sempre surpresa (embora seja possível uma pessoa admirar-se ao espelho, em relação à sua aparência). Transitivamente, admirar significa uma atitude (de admiração) em relação a uma pessoa, obra, ou ação, quando o sujeito é humano. Quando o sujeito é uma ação ou situação e o objeto humano, estamos em face de surpresa novamente, cf. 0 comportamento dele admirou- $a$. Na passiva ${ }^{9}$, os auxiliares estar e ficar estão associados a espanto, enquanto ser indica a atitude mental. Noutros casos é preciso mais do que a estrutura sintática para distinguir entre os dois sentidos de admirar, como é o caso das orações participiais (sem auxiliar expresso) (exs. 1-2), ou a própria nominalização, admiração (exs. 3-5), embora em alguns casos, como em ter/inspirar admiração, o verbo suporte permita facilmente a desambiguação. Repare-se também que as preposições por e de, respetivamente associadas ao verbo e ao nome, são ambíguas, como os exemplos mais uma vez ilustram.

(1) D. Ana Perpétua ficou fascinada pelo espírito fulgurante do poeta, admirado por todos, e admitido na intimidade da família na quinta de Arroios, em Colares.

(2) Langdon parou, admirado por ela conhecer a obscura publicação sobre os movimentos dos planetas e seu efeito sobre as marés.

(3) Grande, porém, senão dolorosa, foi a admiração de Salazar, quando, anos depois, lendo o primeiro tomo da edição das obras de Camões, (...)

(4) O relativamente obscuro general Suharto tem gozado desde então da admiração de Washington.

[9] Estamos naturalmente muito conscientes de que passiva não é mais uma vez uma designação consensual, mas remetemos o leitor para Santos (2014c) para uma descrição das várias escolhas e alternativas possíveis, e qual a escolhida no presente enquadramento. 
(5) Dos montes e das cidades acudiam monges, acudiam mesmo pagãos, para o visitar, uns na admiração de tão espantosa penitência, outros na esperança de serem por ele curados de feridas e males.

Seja como for, criámos várias regras automáticas para lidar com todas as ocorrências relacionadas com a base admirar nos nossos corpos, de maneira a distinguir entre os dois sentidos.

A correta desambiguação de todas as ocorrências exige a revisão humana, o que ainda não foi feito, exceto num único corpo - o Museu da Pessoa - para podermos avaliar o trabalho envolvido e os problemas esperáveis. Na próxima secção descrevemos exatamente os resultados dessa revisão.

\section{[4.1] Descrição quantitativa}

Os resultados obtidos, englobando todo o campo da surpresa e da veneração, encontram-se na tabela 8. (Note-se que existe uma marcação dupla em relação às emoções: as palavras que são quase sempre veículo de uma dada emoção são marcadas com emomin; outras palavras que só em poucos contextos a podem veicular, como emomax. Na revisão, revimos ambos os casos, por isso juntámos os dois valores na tabela.)

\begin{tabular}{lllll}
\hline & emomin+emomax & +medo & +tristeza & Lemas dif. \\
\hline surpresa & $186385+21053$ & 4938 & 362 & $175(98)$ \\
veneração & 39571 & & & 14 \\
\hline
\end{tabular}

TABELA 8: Palavras inicialmente marcadas como surpresa ou veneração em todos os corpos

Em relação a essa tabela, convém indicar que:

- os casos não decididos entre surpresa-saudade-tristeza referem-se a banzo, palavra brasileira de origem africana;

- os casos não decididos entre surpresa-medo referem-se a formas associadas a sobressaltar ou sobressalto.

Estas classificações são feitas automaticamente, não estamos a dizer que não fosse possível, para cada um dos casos, identificar a emoção certa ou predominante. Por outro lado, o altíssimo número de lemas diferentes entre antes e depois da revisão e uniformização ${ }^{10}$ também demonstra as características do material usado.

[10] Juntando diferenças entre as variantes tal como estupefacto e estupefato ou atônito e atónito e retirando muitos casos óbvios de erro no texto original (tais como imprevisibildade ou subito) ou erro do analisador sintático (por exemplo, espasmo como derivado de pasmo, surpreendedora como substantivo em vez da forma feminina do adjetivo surpreendedor). 
Em particular, deve-se acautelar a questão do peso a dar a estudos de riqueza lexical baseados simplesmente no número de lemas distintos. De qualquer maneira, para concretizar, apresentamos em apêndice o número de lemas diferentes considerado, indicando que todos os neologismos e formas criativas que nos pareceram deliberadas foram mantidos - sobretudo porque estamos convictas de que a existência destes casos testemunha a pujança da emoção na língua, concordando com o raciocínio defendido por Baayen \& Renouf (1996). Além disso, convém lembrar que os diminutivos, aumentativos e superlativos não são necessariamente neutros: podem trazer nuances de sentido, e por isso foram contados separadamente.

Quanto à revisão humana do Museu da Pessoa, os números encontram-se na tabela 9 .

\begin{tabular}{lrrl}
\hline & Inicial & Final & Dúvidas \\
\hline admiração & 17 & 46 & 2 maravilhar \\
surpresa & 148 & 118 & 2 maravilhar \\
\hline
\end{tabular}

TABELA 9: Revisão do Museu da Pessoa relativa a surpresa/admiração

Refira-se que há muitos mais casos de admiração na variante brasileira (38 contra 8 casos, mesmo que o tamanho da parte brasileira seja cerca de 3,5 vezes o da portuguesa); também convém salientar que quatro casos de maravilhar foram considerados tanto surpresa como admiração, veja-se dois exemplos:

(6) Bom, essa gruta, eu estava nessa gruta e aí eu fui só me maravilhando com aquilo tudo

(7) E essas empresas ficaram tão tão maravilhadas com o projeto que eles também vão entrar no projeto, provavelmente doar para os clientes deles

Como seria de esperar, a admiração automática pecou (e bastante) por defeito. Por outro lado, o seguinte exemplo ilustra claramente que é preciso fazer regras muito específicas para distinguir as duas frases seguintes, a primeira exprimindo surpresa e a segunda admiração:

(8) Dona Maria da Conceição, eu queria fazer uma pergunta para a senhora que é o seguinte, como a senhora viu toda essa transformação das cidades, do mundo? Muito admirada, mas também vi muito progresso, mas progresso e maldade.

(9) A minha mãe aparecia menos nas coisas públicas, não tinha a preponderância do meu pai na vida comum, da vida da aldeia das coisas públicas, da 
igreja, das festas, mas era uma pessoa extremamente delicada, muito aceite, também na vida comum. Muito admirada, muito carinhosa com os meninos, com os filhos, de uma grande dedicação ao meu pai e sobretudo amorosa, um extremo de afectividade.

\section{[4.2] Comparação de casos complicados}

No âmbito do desenvolvimento do Rêve ${ }^{11}$, a primeira autora escolheu um conjunto de casos que poderiam ser difíceis de classificar dos corpos Museu da Pessoa e OBRAS, e que eram praticamente todos os casos com lema admirar ou admiração, e uns poucos associados à palavra reverência. Essa lista foi depois analisada e todos os casos classificados pela primeira autora, e depois o mesmo foi feito por Cláudia Freitas, revendo a anotação inicial, e pela segunda autora, criando uma anotação alternativa, independente.

Embora os resultados sejam apresentados e discutidos em mais detalhe noutro artigo (Santos et al. 2015), uma conclusão bastante relevante foi a da existência de um conjunto razoável de casos em que mais do que uma aceção foi considerada pelas anotadoras, demonstrando que existem muitas situações em que um item lexical em contexto pode ser vago, ou seja, ter mais do que um dos sentidos e deste modo justificando claramente a partilha do sentidos pelos mesmos itens lexicais.

Exemplos de multiplicidade de sentidos que nos parecem particularmente claros são:

(10) Esse Hilário tinha na montra da oficina dele, em 1945, um carro feito por ele que quem passasse por lá admirava aquela arte .

(11) aqueles dois recentes conhecimentos de Albernaz, embevecidos, boquiabertos e invejosos diante das proezas imaginárias daqueles três militares

(12) Ângelo aos quinze anos já embasbacava os seus ingênuos professores

Outra observação interessante foi a descoberta de um outro sentido de admirar, parafraseável por "olhar com gosto/prazer", e que foi encontrado no OBRAS frequentemente, mas não no Museu da Pessoa. Vejam-se os seguintes exemplos:

(13) Do alto de uma janela como Paul Adam, admira o caleidoscópio da vida no epítome delirante que é a rua

(14) A rigor, era natural admirar as belas figuras

[11] http://www.linguateca.pt/Reve/ 
(15) O meu amigo dividiu a dor com o público; e, se enterrou a mulher sem aparato, não deixou de lhe mandar esculpir na Itália um magnífico mausoléu, que esta cidade admirou exposto, na Rua do Ouvidor, durante perto de um mês.

Com efeito, se em 13 só se pode compreender o prazer de ver ou mirar, em 15 pode-se facilmente também interpretar como admiração.

[5] O OPOSTO DE ADMIRAR

Outra observação interessante refere-se ao oposto de admirar no sentido de venerar: será possível escolher entre desprezar e invejar? Em invejar mantém-se a noção de que o objeto é bom, mas o sentimento que inspira é mau, enquanto em desprezar é simplesmente a atitude (oposta) que é mencionada.

Para tentar responder a esta questão de uma forma empírica, baseando-nos na hipótese de que a antonímia é também uma propriedade textual, como defendido por Justeson \& Katz $(1991,1992)$, medimos a co-ocorrência destes conceitos (lemas), em todos os corpos, e obtivemos 72 casos de co-ocorrência de desprezar e admirar, e 148 de invejar e admirar. Embora a balança penda mais para a inveja, portanto, observámos que às vezes esta é mencionada como um tipo de admiração e não como o seu oposto, cf. exemplos 16 e 17.

(16) (...) ela via com santa inveja e admiração as sobre-humanas forças que imaginava no frade (...)

(17) Entusiástico fã de Mário Soares, José Aparecido de Oliveira revela que o que mais admira, inveja mesmo, no nosso Presidente não é cultura, não é a comunicabilidade, não é a inteligência, não é a glória.

[6] OBSERVAÇÕ ES FINAIS

Quando se abraça um assunto tão interessante e multifacetado como o dos modos de uso de palavras relacionadas ao campo das emoções na língua, é difícil abordálo em todas as vertentes, mesmo quando nos restringimos a uma das vinte que Belinda Maia estudou, ainda por cima contrastivamente. Muito fica por fazer, e limitamo-nos nos parágrafos seguintes a sugerir outros estudos que reputamos de grande interesse.

(i) Um dos aspetos que gostaríamos de explorar futuramente é a dimensão temporal, estudando como variaram as distinções entre o sentido de surpresa e veneração ao longo do tempo e qual a original, usando os corpos Vercial $^{12}$, Colonia (Zampieri \& Becker 2013) e CONDIVPort (Silva 2008). Os

[12] http://alfarrabio.di.uminho.pt/vercial/ 
primeiros dois são corpos de textos essencialmente literários escritos entre 1500 e os anos 30 do século XX; o último é um corpo jornalístico que inclui notícias dos anos 50, 70 e 2000.

Esse estudo poderia ser levado a cabo, estudando, primeiro, a aplicabilidade das regras de distinção entre os dois sentidos já criadas para o corpo Museu da Pessoa (que permitem analisar o uso reflexivo, da passiva, da nominalização, entre outros - ver secção [4]) e, em seguida, a sua interrelação com os vários aspectos estudados na secção [3]: distribuição por pessoa, por tempo, presença em frases negativas, etc.

(ii) Outro estudo que ficou por fazer mas que seria uma sequência óbvia do interesse por esta área seria investigar quais os objetos e os sujeitos associados à admiração, eventualmente selecionando quais as propriedades mais admiradas ou de espantar.

(iii) Finalmente, usando corpos paralelos, seria relevante verificar se estas duas atitudes/emoções teriam traduções interessantes ou influência forte de outra língua.

Mesmo que muito tenha ficado por fazer, do trabalho aqui relatado podemos concluir que, em português, pelo menos nos corpos estudados, o sentido de surpresa é francamente mais frequente que o de veneração, tanto em termos de ocorrências, como em termos da própria riqueza lexical das duas emoções ou atitudes.

Tal não é, contudo, corroborado pela divisão do trabalho entre as palavras associadas à raiz admir-, que, na maioria dos casos, se referem indiscutivelmente ao sentido de reverência (veja-se admirável, admiravelmente, admirador). A própria distribuição do verbo admirar converge nesse sentido (no Museu da Pessoa, em 35 casos, 25 exprimem veneração e 10 surpresa), o que pode dar pistas para a sua evolução futura.

Por outro lado, é interessante verificar que é uma palavra de origem estrangeira, fã que leva indubitavelmente a palma na referência a este sentimento, com as palavras admirador ou admiradora sendo relegadas para um nicho mais antiquado, formal e culto.

Seguindo esta lógica, as autoras confessam-se admiradoras e fãs de Belinda Maia e do seu trabalho sobre as emoções na língua e sobre a comparação entre as duas línguas, e esperam, com esta pequena contribuição, arranjar mais interessados na área e atrair a atenção para a mina de ouro que é o trabalho de Maia (1994/1996).

\section{AGRADECIMENTOS}

Agradecemos à Cláudia Freitas a anotação dos casos referidos no artigo, e ao Eugénio Oliveira e à Maria José Finatto os comentários pertinentes. 
APÊNDICE

Lista, por ordem decrescente de frequência, dos lemas considerados com o sentido de admiração/respeito/veneração:

fã, admirável, admirador, reverência, venerar, deslumbrar, veneração, deslumbramento, admirar, venerável, admiração, reverente, endeusar, admiradora, reverentemente, admiravelmente.

Lista, por ordem decrescente de frequência, dos lemas considerados com o sentido de surpresa:

surpreender, surpresa, surpreendente, inesperado, admirar, súbito, surpreso, admiração, espantar, espanto, imprevisível, imprevisto, sobressalto, perplexo, surpreendentemente, repentino, pasmar, inesperadamente, maravilhar, espantado, admirado, pasmo, atônito, sobressaltar, estupefato, rompante, boquiaberto, pasmado, maravilhado, embasbacar, banzo, subitamente, banzar, aparvalhado, impromptu, imprevistamente, surpresinha, admiradíssimo, espantadíssimo, surpreendedor, súbitamente, espantação, surpreendidíssimo, inesperadíssimo, perplexamente, rompância, espantável, pasmadamente, pasmante, pasmadinho, maravilha, readmirar, aparvalhadamente, espantador, sobressaltozinho, pasmação, sobressaltante, espantadamente, pasmacento, superespantado, perplexante, admiradamente, perplexificação, perplexificar, surpresinhas, pasmático, autoadmiração, admiradinho, superadmirado, surpreendidamente, semipasmado, subitíssimo, estupefactante, maravilhante, sobressaltadamente, perplexar, europerplexo, maravilhadora, espantadinho, sobressaltoso, maravilhadamente, surpresão, surpresíssimo, perplexizante, semiestupefacto, amaravilhar, perplexia, subitização, subitizar, dessurpreendentemente, banzadinho, surprezinha, espantão, subitar, admirandas, pasmadíssimo.

Nota sobre o lema amaravilhar

Possivelmente na origem um erro de digitação, esta frase encontra-se em vários locais na Internete:

Provavelmente o panteísta mais famoso e notável tenha sido o físico alemão Albert Einstein. Seu amaravilhar-se diante da Ciência freqüentemente o estimulava a exaltar uma provável natureza divina inerente a tudo.

Tanto quanto nos foi possível averiguar, provém de uma versão anterior da Wikipédia, mas que foi corrigida, ou seja, retirada desta enciclopédia por conter uma afirmação duvidosa! Contudo, já infetou a Internete e até os corpos da Linguateca... 


\section{REFERÊNCIAS}

Baayen, R. Harald \& Antoinette Renouf. 1996. Chronicling the Times: Productive Lexical Innovations in an English Newspaper. Language 72(1). 69-96.

Freitas, Cláudia, Eduardo Motta, Ruy Luiz Milidiú \& Juliana César. 2014. Sparkling Vampire... lol! Annotating Opinions in a Book Review Corpus. Em Sandra Aluísio \& Stella E. O. Tagnin (eds.), New Language Technologies and Linguistic Research: A Two-Way Road, 128-146. Cambridge Scholars Publishing.

Freitas, Cláudia \& Diana Santos. 2015. Blogs, Amazônia e a Floresta Sintá(c)tica: um corpus de um novo gênero? Em Simone Sarmento, Tony Berber Sardinha, Livia Pretto Mottin \& Ana Maria T. Ibaños (eds.), Pesquisas e perspetivas em lingüística de corpus, 123-150. Mercado de Letras.

Justeson, John S. \& Slava M. Katz. 1991. Co-occurrences of Antonymous Adjectives and Their Contexts. Computational Linguistics 17(1). 1-19.

Justeson, John S. \& Slava M. Katz. 1992. Redefining Antonymy: The Textual Structure of a Semantic Relation. Literary and Linguistic Computing 7(3). 176-184.

Maia, Belinda. 1994/1996. A Contribution to the Study of the Language of Emotion in English and Portuguese: FLUP. Tese de Doutoramento. Versão revista: 1996.

Maia, Belinda \& Diana Santos. 2012. Who is afraid of ... what? - In English and in Portuguese. Em Signe Oksefjell Ebeling, Jarle Ebeling \& Hilde Hasselgård (eds.), Aspects of corpus linguistics: compilation, annotation, analysis 12, s/pp.

Ortony, Andrew, Gerald L. Clore \& Allan Collins. 1988. The Cognitive Structure of Emotions. Cambridge University Press.

Santos, Diana. 1998. A relevância da vagueza para a tradução, ilustrada com exemplos de inglês para português / The relevance of vagueness for translation: Examples from English to Portuguese. TradTerm 5. 41-70, 71-78.

Santos, Diana. 2014a. First steps of Gramateca: a corpus-based grammar initiative for Portuguese, driven by Linguateca. Apresentação na Universidade de Oslo. http://www. linguateca.pt/Diana/download/GramatecaOslo.pdf.

Santos, Diana. 2014b. Gramateca: corpus-based grammar of Portuguese. Em Jorge Baptista, Nuno Mamede, Sara Candeias, Ivandré Paraboni, Thiago A.S. Pardo \& Maria das Graças Volpe Nunes (eds.), International Conference on Computational Processing of Portuguese (PROPOR'2014), 214-219. Springer.

Santos, Diana. 2014c. Podemos contar com as contas? Em Sandra Aluísio \& Stella Tagnin (eds.), New language technologies and linguistic research: a two-way road, 194-213. Cambridge Scholars Publishing. 
Santos, Diana. 2015. Comparando corpos orais (transcritos) e escritos no âmbito da Gramateca. Em Proceedings from the conference Parler les langues romanes/Parlare le lingue romanze/Hablar las lenguas romances/Falando línguas românicas (The ninth GSCP International Conference), University Press Università di Napoli L'Orientale.

Santos, Diana, Rui Pedro Ribeiro Marques, Cláudia Freitas, Cristina Mota \& Alberto Simões. 2015. Comparando anotações na Gramateca, Atas do ELC2014 (Título preliminar). Em preparação.

Santos, Diana \& Cristina Mota. 2010. Experiments in human-computer cooperation for the semantic annotation of Portuguese corpora. Em Nicoletta Calzolari, Khalid Choukri, Bente Maegaard, Joseph Mariani, Jan Odijk, Stelios Piperidis, Mike Rosner \& Daniel Tapias (eds.), Proceedings of the International Conference on Language Resources and Evaluation (LREC 2010), 1437-1444. ELRA.

Santos, Diana \& Cristina Mota. 2015. Emotions in natural language: a broadcoverage perspective. Em apreciação.

Silva, Augusto Soares da. 2008. O corpus CONDIV e o estudo da convergência e divergência entre variedades do português. Em Luís Costa, Diana Santos \& Nuno Cardoso (eds.), Perspectivas sobre a Linguateca / Actas do encontro Linguateca : 10 anos, 25-28. Linguateca.

Zampieri, Marcos \& Martin Becker. 2013. Colonia: Corpus of historical portuguese. Em Marcos Zampieri \& Sascha Diwersy (eds.), Non-standard data sources in corpus-based research, vol. 5 ZSM Studien, 77-84. Shaker.

CONTACTOS

Diana Santos

Linguateca e Universidade de Oslo

d.s.m.santos@ilos.uio.no

Cristina Mota

Linguateca

cmota@ist.utl.pt 